\title{
The Artistic Innovation of Chinese Zodiac Culture in Jingdezhen Ceramic
}

\author{
Han Wei \\ School of Art and Design, Ceramic Institute, Jingdezhen 333000, China \\ 809978823@qq.com
}

\begin{abstract}
Keywords: Chinese zodiac theme; ceramic; artistic innovation.
\end{abstract}
\begin{abstract}
Our ancestors believed that humans and animals were related by blood from the primitive society, and Chinese zodiac culture originated from the ancient Chinese animal worship, totem worship and early astronomy. The Chinese zodiac appeared on the ceramic, the earliest can be traced back to the Banpo ancient painted pottery, neolith pot depicted on a wild boar is excavated in Hemudu, colored pottery depicted on the puppy in unearthed in Xindian, the modeling is concise, people have been able to re-create beasts through imitating the nature, so meet the aesthetic needs of life. After many years, ideological and academic field are unprecedented prosperity, culture and art has also been greatly advance, peoples' aesthetic understanding is improved and strengthened continually, various animal painted pottery, utensils are also widely used in all aspects of people's life. Jingdezhen is famous for porcelain; ceramic is the root of the city. The kiln fire in Jingdezhen has been inherited for over a thousand years, and now it has become the cultural symbol of our Chinese nation. Art must follow times, today's Jingdezhen, the continuous innovative consciousness make the city full of vitality, a group of artists with original spirit and innovative thinking inherit traditional ceramic, at the same time, use all kinds of art forms and ceramic combination to explore constantly. Contemporary Jingdezhen ceramic art bear art which ceramic art as the main line, show the spirit culture thickness of porcelain capital, and its splendid ceramic art achievements.
\end{abstract}

\section{Introduction}

The Chinese zodiac is the twelve Chinese zodiac animals in traditional Chinese folk culture. Chinese zodiac is made up of eleven stems from the nature of animals, which are rat, ox, tiger, rabbit, snake, horse, sheep, monkey, chicken, dog, pig and legendary dragon, and used for record years, the order is: the rat, ox, tiger, rabbit, dragon, snake, horse, sheep, monkey, chicken, dog, and pig.

There are many wording about the zodiac, most are folk tales. The Chinese zodiac is applied to life, which can date back to ancient times. In ancient times, there is a plate, the plate is enclosed with zodiac pattern, this offer the twelve Chinese zodiac graphic design at any time of change and transformation. In the Song dynasty, a large number of Chinese zodiac graphics appeared on the coin, Chinese zodiac are widely used in calligraphy, painting, clay sculpture, sculpture, porcelain all kinds of media, Chinese zodiac become the one of the most popular decorative arts subjects with people.

Compared with traditional art ceramic, modern ceramic art has enhanced the appreciation function of works and has decorative value. The decorative value of ceramic has a process that is gradually recognized by people. China' ancient ceramic have articles of everyday use and decorations. The decorations are decorative in a certain sense, but still have a "practical" shape. It can be traced back to the late Ming dynasty porcelain plate painting; it is the pure decorative meaning of ceramic. The porcelain was developed into the late Qing dynasty and early republic of China, and there are two varieties of light crimson and new powder color, and they make people realize the decorative value of ceramic. The foundation of modern ceramic art is to appreciation function, which undoubtedly establishes the future for its decorative value. The theme of art ceramic is old, the shape is single and homogeneous, on the one hand is because our country is still in the early stage of development, modern and contemporary art ceramic industry development is not yet mature, on the other hand, the lack of innovative consciousness is the important reason. 
China has always been regarded as the country of porcelain, Jingdezhen is the center of ceramic art in China, which has a profound history and culture of ceramic, and has been kept alive for thousands of years. Historically, every era has its own art, but each time does not exist in isolation, they are connected, the first generation of art will always give the art of the offspring with huge impact. Thousands of years history prove ceramic decoration art has its own rules, we should seriously study the law, inherit and draw lessons from national history tradition and other outstanding art. Therefore, in theory and practice, ceramic decoration research needs to further emancipate the mind, accelerate innovation, and create good works with distinctive times and Chinese style.

Contemporary ceramic art in Jingdezhen has changed a lot, no matter in ceramic materials, technology, craft or artist's creative idea compared with traditional ceramic art. Reasonable inheritance and innovation of contemporary ceramic art, following the "degree" between them, then we can effectively promote the development of ceramic culture art in China.

\section{The Inheritance of Traditional Ceramic Culture}

The traditional ceramic art can be planned as static art from. It focuses on the unique ceramic language and the aesthetics as its purpose. Song yingxing summed up the ancient Jingdezhen's handmade porcelain technique into seventy-two processes, and each procedure was simplified. so The detailed division improve the efficiency of the porcelain making, Jingdezhen porcelain became the best of China, these seventy-two processes have been passed down to this day, which has become the unique art ceramic art language. Secondly, the traditional ceramic art of Jingdezhen, which is one of the outstanding aesthetic creations of the Chinese nation, also reflects the aesthetic consciousness of the nation and has unique aesthetic value. In ancient China, the elegance and dignified character were highly respected, and it is the definition of beauty in Chinese tradition. Traditional ceramic art as a witness of the Chinese nation for thousands of years civilization, has the profound culture connotation, through mud and fire melt, which has become the symbol of Chinese culture, and it is worthy of our inheritance.

\section{The Development of Ceramic Art Needs Innovation}

Fresh and elegant green flowers, colorful painting, gorgeous color glaze, beautiful sculptures, these are treasures of Chinese culture and art, and they are the pride of the Jingdezhen. People who know the history of Jingdezhen ceramic development know that for more than one thousand years, it is because of continuous innovation, Jingdezhen won the reputation of the world porcelain capital. From the shadow green porcelain of the Song Dynasty, the green flowers of the Yuan Dynasty, the five colors of the Ming Dynasty, the pink and enamel colors of the Qing Dynasty, there are new things in every dynasty. In addition to technological innovation, there are new things in the content, drama mythology, regional customs, scenery figures, life scenes and so on, from the process to the content, its development and changes are very rich. If the Song Dynasty to the Yuan Dynasty, there only the shadow green porcelain, that is too limited, then there is no Jingdezhen. Therefore, from a historical point of view, Jingdezhen should keep its reputation, maintain its status as the porcelain capital, and maintain its leading position in the ceramic technology and cultural field, It is necessary to innovate constantly and not lie on the achievements of the predecessors, if stagnant, it cannot adapt to the development of the times.

In the heritage of ceramic culture, it is a necessary process to inherit the artistic achievements of the ancestors, and innovation is the ultimate foothold of cultural heritage. The heritage and innovation of ceramic culture complement each other. For the current and future ceramic art of Jingdezhen, no matter the decorative technique, the theme, the material technology and the innovation of the tool, the burning, and the display mode, these are expected by people. 


\section{Inherit Ancient Culture and Innovate Porcelain}

Inheritance and innovation is an eternal topic, which is more important for ceramic art with a long history and profound heritage. The ceramic art of Jingdezhen is cultivated in the unique cultural soil of our country, and it is the profound cultural atmosphere and connotation that has made it endure for thousands of years. The development of contemporary ceramic art should be based on adhering to the basic foundation of tradition; otherwise it will be without source of water and tree without roots. However, inheritance is not to indiscriminately imitate traditional decoration, and rigidly use traditional ceramic technology, but to study, study, analyze, inherit the most precious traditional ceramic art essence left by ancestors. Then we integrate into the times spirit of contemporary ceramic art of the spirit. After all, modern people are not the ancients, they need to be integrated into the modern context, and the cultural thinking and aesthetic experience of modern people can be displayed, we can learn from other art forms. Now tens of thousands of artists are engaged in ceramic art creation in Jingdezhen, their artistic achievements art idea, creation way are used in ceramic art creation, the combine ceramic technology, techniques and concepts, and get a lot of unexpected results. However, this kind of lesson and learning is not a mechanical application; it cannot be doctrinarism. "When everyone inherits result, the results can only be developed in a limited scope, it will never be able to break through and innovate, but if the inherit the innovative mind before civilization, it would be bigger." It can be said that innovation is the inexhaustible driving force for the development of ceramic art, the development of contemporary ceramic art needs to be innovative, but it must be innovated by inheriting "soul" from tradition.

Jingdezhen zodiac porcelain has been used as an important symbol product and material communication medium of auspicious ideas. The auspicious words, porcelain plate, porcelain bottle, porcelain sculpture, ceramic accessories and other technique of expression, inherit a variety of porcelain processing technology with unique characteristics, gradually forms the symbol and aesthetic taste of Jingdezhen's zodiac porcelain. At the same time, in Jingdezhen zodiac porcelain art, its performance scheme breaks through the traditional aesthetic characteristics and modeling principle, integrate rich local characteristics and popular aesthetic concept, truly reflects the mass aesthetic taste and ideal. For example, twelve Chinese zodiac signs, shape break through traditional aesthetic style. The image is simple and vivid, use bright festive colors, match generous and concise decoration ceramics, create a common popular art form, and become the Jingdezhen zodiac porcelain classic.

The Chinese zodiac culture originates from life, and its theme is full of folk-custom, belief and philosophy, which is an expression and appeal of people's inner feelings. Of course, the zodiac porcelain is a symbol of good luck, peace and tranquility. In today's era, The auspicious idea of praying for blessings is deeply rooted in every citizen's heart, and integrated into the social life, customs, and forms the unique national cultural identity and sense.

Today, Jingdezhen's zodiac porcelain has a wide variety of themes and rich connotations. Jingdezhen zodiac porcelain shape and modeling is in some sense, is their most popular and most cordial aesthetic emotional factors, and reflects material carrier and object symbol meaning in the real life pray for peace and happy life. Accordingly, Jingdezhen zodiac porcelain design can consciously in the form of modeling language, combined with various auspicious image, and highlights survival admire and pray for blessing, also pays attention to the Jingdezhen porcelain glaze color, emphasize the use of color and decorative symbolism to satisfy the public's psychological needs and aesthetic enjoyment. With the improvement of people's aesthetic cognition, the Chinese zodiac cultural art tends to be diversified, interesting and life-changing, Jingdezhen zodiac porcelain in the process of inheritance and transformation, has lost and downplayed the primitive religious beliefs such as luck or disaster, cultural psychology has been translated into praying for good fortune..

Actually " economic globalization of today's world", regional communication gradually increase "cultural differences is becoming more and more small, Chinese ceramics must find one own way, which should not only keep the independence of the Chinese traditional culture, and show the modern characteristics of the road of Chinese ceramics. 
Jingdezhen ceramic face the world has made outstanding contributions to the spread and exchange of culture, Demand for ceramics is growing worldwide, more and more foreigners are eager to understand the traditional Chinese culture.

\section{Conclusion}

Promote the ceramic culture, develop and expand the Chinese zodiac culture, to realize the combination of these two is promising, as is known to all, a unique cultural phenomenon can form a good culture industry market, in this case, We take ceramic as the carrier of Chinese zodiac culture which is unfamiliar to foreign countries, promote more countries abroad, it will drive the Chinese ceramic industry and the export of Chinese zodiac culture industry, and even the export of other traditional industry and the traditional culture, at present, many overseas Chinese have recognized the unique culture of the broader business in China.

To sum up, in order to develop and expand the era characteristic and Chinese traditional culture, realize the combination of ceramic culture and the Chinese zodiac culture, not only is based on history, and has extensive business opportunities, and it is a developing potential in future

\section{Acknowledgements}

Project source: Research on innovative characteristics of Jingdezhen Chinese Zodiac ceramic culture in Jiangxi Province.

Project source: art planning project of Department of Culture of Jiangxi Province.

Project number: 752005-030

\section{References}

[1]. Li Xiongde, Research on Developing Strategies of Jingdezhen Ceramic Creative Culture Industry [J], China Ceramic Industry, 2008-06.

[2]. Q Xiaoli, Relationship between Jingdezhen Ceramic Culture and Ceramic English [J], Journal of Jingdezhen College, 2003.

[3]. L Hu, Establishment of Jingdezhen Ceramic Cultural and Creative Industry System [J], Jiangsu Ceramics, 2009.

[4]. W Wang, H Qi, J Zhou; Integration and Development of Jingdezhen Ceramic Cultural Resources [J];Journal of Hebei University of Economics and Trade; 2003-01.

[5]. X Li; Research On Developing Strategies Of Jingdezhen Ceramic Creative Culture Industry, China Ceramic Industry, 2008. 